\section{Parental perceptions of health- related quality of life of Albanian children with epilepsy}

\author{
Efrosini Kalyva, ${ }^{1}$ Erika Melonashi \\ 1 City College, International Faculty of the \\ University of Sheffield, Thessaloniki, \\ Greece; 2European University of Tirana, \\ Albania
}

\begin{abstract}
Epilepsy adversely affects the health-related quality of life (HRQoL) of children living with it. Even though almost $80 \%$ of children with epilepsy live in developing countries very little research has been conducted with the specific population. The present study took place in Albania and aimed to investigate parental perceptions of the HRQoL of their children with epilepsy. Considering the well-defined gender roles in the Albanian traditional family it was expected that mothers and fathers reports of their children's HRQoL would differ. Results showed no differences in maternal and paternal reports; instead there was a moderate correspondence between the reports across all dimensions. Parents also reported the highest scores of HRQoL in the interpersonal dimension and the lowest scores in the intrapersonal dimension. The findings have implications in the context of future research and also medical care for children with epilepsy in Albania.
\end{abstract}

\section{Introduction}

Epilepsy is one of the chronic illnesses with the greatest negative impact on quality of life especially for children.1,2 Studies have reported that compared to healthy controls, children with epilepsy exhibit more behavioral problems, depressive symptoms, social withdrawal, aggression etc. ${ }^{3-6}$ Factors such as comorbidity, number of medications and frequency of seizures are also highly related to diminished quality of life in children with epilepsy. ${ }^{7-9}$ In this context several studies have examined quality of life as related to the specific health/illness status and have focused on the health-related quality of life construct (HRQoL); either general or specific models of HRQoL have been used, which have defined this construct as a multidimensional indicator of physical, social and psychological functioning of the individual in the context of the specific disease. ${ }^{10-13}$

Cross country research has provided evidence that $80 \%$ of all children with epilepsy live in developing countries, such as Albania, where they might also lack medical treatment and psychological support. ${ }^{14}$ However, the issue of medical treatment is not as problematic, as the indifference towards the quality of life of children suffering from this disease. Although evidence from Albania shows increasing rates of several neurological disorders (including epilepsy) the corresponding efforts to provide psychosocial support are practically non-existent. ${ }^{15}$ Indeed, the traditional medical model still focuses mainly on controlling the disease symptoms, without considering the psychosocial aspects of the illness and without engaging the parents in decision-making regarding their children's illness. ${ }^{16}$

The importance of parental involvement in decision-making regarding medical treatment is crucial, since they can provide health professionals with valuable information about their children. ${ }^{17}$ Parents is believed to play an equally important role in providing useful information about their children's HRQoL, which is why many studies use proxy parental reports. ${ }^{18,19}$ Evidence indicates that parental and child self reports are significantly correlated, although the former tend to report lower HRQoL as compared to their children.20 However, parental reports are especially useful in cases when children are too young or their involvement in the study poses ethical issues. ${ }^{17}$ Research has shown that mothers and fathers actually provide similar reports of their children's HRQoL (epilepsy and other chronic childhood illnesses).21-24

Nonetheless, these findings might not apply to different cultural contexts (e.g., Albania), where gender roles in the family are especially well-defined; for instance, evidence from Albania suggests that the mother still is the primary (and sometimes the only caregiver), while the father figure is still the main or only breadwinner. ${ }^{25}$ In this context, it is important to examine whether the findings from other countries, referring to a high correspondence of maternal and paternal reports also apply to Albania. Therefore, the aim of the present study was to assess whether Albanian mothers and fathers hold similar perceptions of the HRQoL of their children with epilepsy.

\section{Materials and Methods}

\section{Procedure and participants}

Ethical approval for the study was granted by the Ethics Committee of City College, International Faculty of the University of Sheffield. Additionally, formal written permission was obtained by the State Hospital Director of Korca, where the study was conducted.
Correspondence: Efrosini Kalyva, City College, International Faculty of the University of Sheffield, Psychology Department, 24 Proxenou Koromila Street, 54622, Thessaloniki, Greece. Tel/Fax: +30.231.026.9096.

E-mail: kalyva@city.academic.gr

Key words: Health-related quality of life; Albania; epilepsy; children; parents.

Acknowledgements: The authors would like to thank the parents who participated in the study, as well as the clinicians and practitioners for their help and support.

Contributions: both authors contributed equally.

Conflict of interest: the authors declare no potential conflict of interest.

Received for publication: 18 January 2014.

Revision received: 20 Februay 2015.

Accepted for publication: 20 Februay 2015.

This work is licensed under a Creative Commons Attribution NonCommercial 3.0 License (CC BYNC 3.0).

(C) Copyright E. Kalyva and E. Melonash, 2015 Licensee PAGEPress, Italy

Health Psychology Research 2015; 3:2244 doi:10.4081/hpr.2015.2244

Participants were parents of children diagnosed with epilepsy, who were contacted by the researchers during routine clinical visits at the hospital (the pediatric neurologist office). All children were diagnosed with epilepsy by the pediatric neurologist and were taking medication for this specific disorder. The researchers explained the study to the parents who were asked to sign the informed consent form if they agreed to participate. The researcher also obtained the parents' permission to get chart information by the neurologist regarding their children's age, gender and frequency of seizures.

Parents were led to a quiet room, where they were given the data sheet and the questionnaire. The data sheet asked information about the age, gender, and education of the parent. Participants were encouraged to ask any questions during the completion of the questionnaire. In cases when only one of the parents was present and the other could not come to the clinic even at a later date, the researchers asked the person present to take a copy (consent form, data sheet and questionnaire) home and return it completed. All questionnaires were returned back completed. This was due to the personal relationship that was built in time between the researchers and the parents, as well as to the fact that the doctors encouraged the parents to participate in the 
study. The final sample consisted of 102 parents (51 mothers and 51 fathers) of 51 children diagnosed with epilepsy. The mean age for mothers was 34.8 years ( $\mathrm{SD}=3.21$ ) and for fathers 41.1 years $(\mathrm{SD}=6.37)$. Only $20 \%$ of the parents had higher education (12 years), while the remaining $80 \%$ had only the obligatory 8 year education. Out of the 51 children, 23 were boys and 28 were girls, aged between 6 and 12 years old $\left(M_{\text {age }}=8.75, \mathrm{SD}=1.97\right)$. In terms of seizure frequency the neurologist (based on the chart records) reported a range from zero to five seizures during the last year $\left(M_{\text {seizures }}=1.74, \mathrm{SD}=1.40\right)$.

\section{Materials}

The present study used the HRQoL questionnaire. ${ }^{26}$ This questionnaire is a disease specific questionnaire, i.e. it could be used only in studies on epilepsy. It is a proxy report measuring HRQoL of children with epilepsy as perceived by their parents. Thus, parents are asked to answer the way they think their child would answer. The parent proxy report scale consists of 5 subscales assessing the following domains: Interpersonal, Future worries, Present worries, Intrapersonal and Secrecy. The Interpersonal subscale assesses the social consequences of epilepsy; it includes items asking on how peers treat these children, whether they have friends etc. Examples include: Some kids with epilepsy think that other kids treat them differently. Future and Present Worries scales include present and future limitations (e.g. not being able to drive when grown-up) and risks (e.g. getting hurt) associated to epilepsy. Examples included: Some kids with epilepsy feel scared about the future. The Intrapersonal subscale includes difficulties in handling emotions, problems with attention, memory etc. Examples included: Some kids with epilepsy get angry easily. Finally, the Secrecy subscale assesses the willingness of children to discuss about the disease or to disclose to others the fact of being sick. Examples included: Some kids feel OK telling people about their epilepsy.

Each of the five domains is assessed by five items, adding up to a total of 25 items. The test is structured in the following way: there are two options for each item and the participant is asked to choose one and then check on the same side whether it is true or sort of true. This double-checking offers the opportunity to think well of the response given and not just choose the first option coming to mind. ${ }^{26}$ The overall score ranged from a minimum of 25 to a maximum of 100 , while the score for each subscale ranged from a minimum of 5 to a maximum of 20. Higher scores showed a higher HRQoL. The Cronbach's coefficient alpha values varied from 0.60 to 0.80 ; more specifically, the interpersonal and intrapersonal subscales had the highest alpha values, approxi- mately 0.8 . The secrecy and worries scales (present and future worries) on the other hand had alpha values in the range 0.6 to 0.68 , which though not high, are still acceptable values for reliability. Moreover, these results are comparable to the authors' original reports (e.g., Chronbach's alpha of 0.64 for Present Worries). ${ }^{26}$ The questionnaire was translated into Albanian; the back-translation into English as well as the simplicity of the items (the wording was the same as that of the child version of the questionnaire) ensured the correctness of translation. A pilot study was conducted with four participants in order to check the accuracy of the translation and to ensure that the items were comprehensible and no revisions were required. However, a point that should be taken into consideration when interpreting the results is that this questionnaire has not been standardized in Albanian.

\section{Statistical analysis}

Descriptive analyses (means, standard deviations, Skewness and Kurtosis values) were run for all variables of interest (the five subscales and total scores). Skewness and Kurtosis values were within the acceptable range for all of the variables (from -1.35 to $2.9)$, suggesting there were no major violations of normality assumptions. In order to examine the extent to which parents agreed on their reports of the several HRQoL dimensions, intra-class correlations (ICC) were conducted. Maternal and paternal reports of HRQoL were also compared by using pairedsamples t-tests.

Also to examine the effects of demographic variables (age, gender of children) and seizure frequency two multivariate regression analyses were conducted with age, gender, and seizure frequency as independent variables and HRQoL total scores (for mothers and fathers separately) as the dependent variables. Also the univariate effects of these variables on parental perceptions of HRQOL (both mothers and fathers) were examined.

\section{Results}

Intraclass correlation analyses revealed that mothers and fathers held similar perceptions about the HRQoL of their children with epilepsy as evident both from the significant positive correlations (ranging from ICC $=0.75$ to ICC $=0.84, \mathrm{P}<0.001)$ and from the lack of statistically significant differences between mothers' and fathers' reports across all dimensions of HRQoL (Table 1). In terms of the specific dimensions, the highest scores (and hence higher HRQoL were reported in the interpersonal dimension $M=14.69$ ( $\mathrm{SD}=4.78)$ and the lowest scores in the intrapersonal dimension $M=9.49$ (SD=3.73), but there were no statistically significant differences between the reports of mothers and fathers in all subscales as is evident in Table 1.

The regression models with age, gender and seizure frequency as independent variables and HRQoL as dependent variable were insignificant. Also the univariate effects of these three variables on parental perceptions of HRQoL were not significant.

\section{Discussion}

The purpose of the present study was to assess parental perceptions of health-related quality of life of their children with epilepsy. The study compared mothers' and fathers' reports on quality of life to examine both relationships and differences on HRQoL. Results showed no significant differences between maternal and paternal reports of HRQoL; also the reports were moderately to highly correlated across all dimensions. Additionally results showed that both parents reported the highest levels of HRQoL in the interpersonal domain and the lowest scores in the intrapersonal one.

These findings were in accordance with studies from developed countries, which have

Table 1. Means, standard deviations, intra-class correlations and paired samples t-tests for perceived health-related quality of life of children with epilepsy as reported by their mothers and fathers.

\begin{tabular}{lcccc} 
Test scores & \multicolumn{2}{c}{ Mean (SD) } & ICC & $\begin{array}{c}\text { Paired samples } \\
\text { t-tests }\end{array}$ \\
Total scores & $63.50(7.15)$ & $62.92(6.91)$ & $0.75^{*}$ & 0.65 \\
Interpersonal & $14.69(4.78)$ & $14.02(4.25)$ & $0.84^{*}$ & 1.4 \\
\hline Future worries & $12.55(2.62)$ & $12.57(2.34)$ & $0.75^{*}$ & -0.06 \\
Present worries & $13.24(4.55)$ & $13.37(4.07)$ & $0.83^{*}$ & -0.30 \\
\hline Intrapersonal & $9.49(3.73)$ & $9.17(3.54)$ & $0.80^{*}$ & 0.75 \\
Secrecy & $13.33(2.84)$ & $13.56(2.84)$ & $0.84^{*}$ & 0.79 \\
\hline
\end{tabular}

Significance level: ${ }^{*} \mathrm{P}<0.001$. ICC, intra-class correlations. 
found no gender differences in parental reports of HQoL of their children.21-24 Therefore, Albanian mothers and fathers of children with epilepsy tend to have similar perceptions of HRQoL of their children across all dimensions. However, parental reports showed the highest correspondence in the Interpersonal dimension of HRQoL and the lowest correspondence in the Future Worries dimension. The interpersonal dimension refers mainly to behaviors that are observable, such as relationships with peers, ability to form friendships, as well as aggressive behavior. 27,28 Therefore a high correspondence on this dimension is not surprising. ${ }^{29}$ On the other hand, the Future Worries dimension is not as accessible or directly observable, since it refers to worries expressed by the child over the future (e.g., not being able to drive a car when they grow up). Thus, reports on this particular dimension might grossly depend on the kind of relationship they have built with the child, e.g., how much they talk to each other over these issues. Hence, in this dimension mothers and fathers might display perspectives that do not correspond as highly as the reports in the interpersonal dimension.

Even so, in terms of overall evaluations mothers' and fathers' reports do not differ significantly, a finding which is quite important both in the context of research and practice. Nonetheless, this finding does not imply that maternal and paternal reports might be used interchangeably, since there is no evidence of the correspondence of these reports with the child's self-reports. Indeed, several authors draw attention to the extra source of variance due to differing concordance of maternal and paternal reports with the child's self-report. ${ }^{21,24}$ Unfortunately the present study could not test the concordance of parental reports with the child's own reports but future studies should consider the use of child self-reports in order to get more solid conclusions.

In the context of reports on the several dimensions of quality of life, a secondary finding (which is nonetheless worth mentioning) refers to the low HRQoL scores reported by both parents on the intrapersonal domain. Hence according to parental perceptions, there are important impairments of their children as regards both cognitive abilities (memory and attention) and ability to control emotions (anger, anxiety, irritability). Studies have repeatedly demonstrated that indeed children with epilepsy have cognitive and emotional problems, which might also be related to the side effects of the medication they are taking. ${ }^{7-9}$ Nonetheless, the lowest scores reported on this dimension might also be indicative of the fact that these children are not getting the appropriate psychological support or cognitive training to help them overcome these difficulties. This aspect should be explored in further research because it goes beyond the scope of the present study.

The present study has several limitations, which need to be discussed. Considering that only two-parent families participated, the findings of this study could not be representative of other more nontraditional families, e.g., one parent families. The stressors in this kind of families might be quantitatively as well as qualitatively different, considering that only one parent has to hold the entire burden. ${ }^{30}$ Reports from mothers and fathers could also largely differ in one-parent families, depending on who is looking after the child. Another limitation applying to the findings in general, is that no control was undertaken on social desirability effects. For instance, parents might have reported a higher HQoL than the actual one. This suggestion derives from the fact that the study was conducted in a medical clinic. Parents would probably be refrained from expressing negative attitudes that might indirectly involve the doctor; it would be rather more acceptable for them to report as if things are generally going moderately well.

Despite the several limitations, the findings of the present study are important in the context of providing information on the parents' perspectives on HRQoL of Albanian children with epilepsy. Results showed that contrary to the expectation, Albanian mothers' and fathers' reports corresponded to each other; nonetheless these reports might not be interchangeably used unless the correspondence with child self reports is first examined.

\section{References}

1. Baker GA. Assessment of quality of life in people with epilepsy: some practical implications. Epilepsia 2001;42:66-9.

2. Baker GA. The psychosocial burden of epilepsy. Epilepsia 2002;43:26-30.

3. Ekinci 0, Titus JB, Rodopman AA, et al. Depression and anxiety in children and adolescents with epilepsy: prevalence, risk factors, and treatment. Epilepsy Behav 2009;14:8-18.

4. Mensah SA, Beavis JM, Thapar AK, et al. A community study of the presence in anxiety disorder in people with epilepsy. Epilepsy Behav 2007;12:118-24.

5. Plioplys S, Dunn DW, Caplan R. 10-year research update review: psychiatric problems in children with epilepsy. J Amer Acad Child Psy 2007;46:1389-402.

6. Rantanen K, Timonen S, Hagstrom K, et al. Social competence of preschool children with epilepsy. Epilepsy Behav 2009;14:33843.

7. Davison GC, Neale JM, Kring AM. Abnormal psychology. 9th ed. Hoboken:
Wiley \& Sons; 2004.

8. Miller V, Palermo TM, Grewe S. Quality of life in pediatric epilepsy: demographic and disease related predictors and comparison with healthy controls. Epilepsy Behav 2003;4:36-42.

9. Williams J, Steel C, Sharp GB, et al. Parental anxiety and quality of life in children with epilepsy. Epilepsy Behav 2003;4:483-6.

10. Bakas T, McLennon SM, Carpenter JS, et al. Systematic review of health-related quality of life models. Health Qual Life Out 2012;10:134-46.

11. Simon AE, Chan KS, Forrest CB Assessment of children's health-related quality of life in the United States with a multidimensional index. Pediatrics 2008; 121:e118-26.

12. Taylor RM, Gibson F, Franck LS. A concept analysis of health-related quality of life in young people with chronic illness. J Clin Nurs 2008;17:823-33.

13. Till JE, Osoba D, Pater JL, et al. Research on health-related quality of life: dissemination into practical applications. Qual Life Res 1994;3:279-83.

14. Pal DK. Epilepsy control in the $21^{\text {st }}$ century: hidden impact on children and families. Child Care Hlth Dev 2003;29:233-6.

15. Kruja J, Beghi E, Zerbi D, et al. High prevalence of major neurological disorders in two Albanian communities: results of a door-to-door survey. Neuroepidemiology 2012;38;138-47.

16. Hajdini G, Harxhi A, Ylli A, et al. Health in Albania: national background report. Institute of Public Health. Faculty of Medicine at University of Tirana, Tirana; 2009.

17. Ronen GM, Rosenbaum P, Law M, et al. Health related quality of life in childhood disorders: a modified focus group technique to involve children. Qual Life Res 2001;10:71-9.

18. Speechley K, Ferro MA, Camfield CS, et al. Cognition and quality of life in children with new onset epilepsy. Neurology 2012;79:1548-55.

19. Taylor J, Jacoby A, Baker GA, et al. Selfreported and parent-reported quality of life of children and adolescents with newonset epilepsy. Epilepsia 2011;52:1489-98.

20. Haneef Z, Grant ML, Valencia I, et al. Correlation between child and parental perceptions of health-related quality of life in epilepsy using the PedsQL.v4.0 measurement model. Epileptic Disord 2010;2:275-82.

21. Jozefiak T, Larsson B, Wichstrøm L, et al. Quality of life as reported by school children and their parents: a cross-sectional survey. Health Qual Life Out 2008;6:34-6.

22. Perrin EC, Lewkowitz C, Young MH. 
Shared vision: concordance among fathers, mothers and pediatricians about unmet needs of children with chronic health conditions. Pediatrics 2000;105:277-85.

23. Sabaz M, Cairns DR, Lawson JA, et al. The health-related quality of life of children with refractory epilepsy: a comparison of those with and without intellectual disability. Epilepsia 2001;42:621-8.

24. Weitkamp K, Daniels J, Rosenthal S, et al. Health-related quality of life: cross-informant agreement of father, mother, and self-report for children and adolescents in outpatient psychotherapy treatment. Child
Adol Ment Health 2013;18:88-94.

25. Sulejmani M. Ndryshimet në familjen shqiptare si pasojë e dinamikës së proceseve shoqërore. In: Mustafa B, Ibrahimi Z, Krifca M, eds. Tetovë: Studime Albanologjike; 2011. pp. 183-192.

26. Ronen GM, Streiner DL, Rosenbaum P, et al. Health related quality of life in children with epilepsy: Development and validation of self-report and parent-proxy measures. Epilepsia 2003;44:598-12.

27. Austin JK, Dunn DW, Caffrey HM, et al. Recurrent seizures and behavior problems in children with first recognize seizures: a prospective study. Epilepsia 2002;43:1564-
73.

28. Dunkley C, Waldron B, Ahmad N, et al. An observational study investigating the health provision for children with epilepsy within secondary schools in Eastern Midlands, UK. Child Care Hlth Dev 2003;29:539-44.

29. Eiser C, Morse R. Can parents rate their child's health-related quality of life? Results of a systematic review. Qual Life Res 2001;10:347-57.

30. Bonney JF, Kelley ML, Levant RF. A model of fathers' behavioral involvement in child care in dual-earner families. J Fam Psychol 1999;13:401-15. 